\title{
Dampak Beban Kerja Coder yang Tinggi terhadap Ketidakakuratan Kode Diagnosis
}

\author{
Warsi Maryati ${ }^{1 *}$, Indriyati Oktaviano Rahayuningrum ${ }^{2}$, Niar Perdana Sari ${ }^{3}$ \\ ${ }^{123}$ Fakultas Ilmu Kesehatan, Universitas Duta Bangsa Surakarta \\ Email: ${ }^{1}$ warsi_maryati@udb.ac.id, ${ }^{2}$ indriyati_oktaviano@udb.ac.id, \\ ${ }^{3}$ niar_perdana@udb.ac.id
}

\begin{abstract}
Dr. Moewardi General Hospital is a fully accredited hospital. Based on the results of a preliminary survey of 10 medical record documents in the Melati ward, $40 \%$ are inaccurate documents. This study aims to determine the relationship of coder workload with the accuracy of the diagnosis code in inpatients of the jasmine ward at Dr. Moewardi in 2018. This research is an analytic study with cross sectional approach. The sample in this study were 99 medical records of inpatient Melati ward with proportionate stratified random sampling technique. Data management by collecting, editing, coding, classification, tabulating, analysis and presenting data.The percentage of the workload is low at 60\% (59 documents) while the workload is high at 40\% (40 documents). Percentage of accuracy of Melati ward code $59 \%$ (58 documents) while inaccuracy is $41 \%$ (41 documents). The data is processed using the chi square and show that $p=0.01$ so that $p<0.01$. The conclusion drawn is that Ho is rejected and Ha is accepted, meaning that there is a relationship between the workload of the coder and the accuracy of the diagnosis code. The suggestion for hospitals should plan and analyze the workload of the coder in each ward.
\end{abstract}

Keywords: workload, accuracy, code, diagnosis

\begin{abstract}
Abstrak
Rumah Sakit Umum Daerah Dr. Moewardi merupakan rumah sakit terakreditasi Paripurna. Berdasarkan berdasarkan hasil survei pendahuluan terhadap 10 dokumen rekam medis di bangsal Melati menunjukkan bahwa $40 \%$ tidak akurat. Penelitian ini bertujuan untuk mengetahui hubungan beban kerja coder dengan keakuratan kode diagnosis pada pasien rawat inap bangsal melati di Rumah Sakit Umum Daerah Dr. Moewardi tahun 2018. Penelitian ini merupakan penelitian analitik dengan pendekatan cross sectional. Sampel dalam penelitian ini sebanyak 99 dokumen rekam medis rawat inap bangsal Melati dengan teknik pengambilan sampel proportionate stratified random sampling. Pengelolaan data dengan collecting, editing, coding, classification, tabulating, analisis dan penyajian data. Persentase beban kerja rendah sebesar 60\% (59 dokumen) sedangkan yang beban kerja tinggi sebesar 40\% (40 dokumen). Persentase keakuratan kode bangsal Melati 59\% (58 dokumen) sedangakan ketidakakuratan sebesar $41 \%$ (41 dokumen). Data tersebut diolah dengan menggunakan uji statistik chi square dan menunjukkan bahwa $p=0,01$ sehingga $p<0,01$. Kesimpulan yang diambil adalah Ho ditolak dan Ha diterima, artinya ada hubungan antara beban keja coder dengan keakuratan kode diagnosis pasien rawat inap di Rumah Sakit Umum Daerah Dr. Moewardi Tahun 2018. Saran bagi rumah sakit sebaiknya merencanakan dan menganalisis beban kerja coder di masing-masing bangsal.
\end{abstract}

Kata kunci: beban, kerja, keakuratan, kode, diagnosis

\section{PENDAHULUAN}

Rumah Sakit adalah institusi pelayanan kesehatan yang menyelenggarakan pelayanan kesehatan perorangan secara paripurna yang menyediakan pelayanan rawat inap, rawat jalan, dan gawat darurat (Undang-undang RI No. 44, 2009).

Surat Keputusan Menteri Kesehatan Nomor : 377/ MenKes/SK/III/2007 tentang Standar Profesi Perekam Medis dan informasi Kesehatan menyatakan bahwa salah satu atau kompetensi yang harus dimiliki oleh perekam medis adalah klasifikasi dan kodefikasi penyakit, masalah-masalah yang berkaitan dengan kesehatan dan tindakan medis. Selama beberapa tahun, penggunaan prosedur dan istilah penyakit yang berbeda-beda mengakibatkan pengumpulan dan pengolahan data morbiditas dan mortalitas menjadi tidak akurat.

Sistem klasifikasi penyakit merupakan pengelompokan penyakit-penyakit yang sejenis ke dalam 
satu grup kode penyakit sejenis sesuai dengan International Statistical Classification of Disease and Related Health Problems revisi 10 (ICD-10) untuk istilah penyakit dan masalah yang berkaitan dengan kesehatan (Kasim, 2011).

Menurut Sudra (2014) pemahaman petugas tentang bahasa terminologi medis dan beban kerja dapat mempengaruhi keakuratan kode. Beban kerja tersebut terlihat dari jumlah berkas rekam medis pasien yang telah dikode setelah mendapatkan pelayanan kesehatan di rumah sakit per hari. Penetapan kode diagnosis pasien rawat jalan yang akurat juga perlu diperhatikan informasi tambahan seperti jenis kelamin, umur, kehamilan, riwayat penyakit, komplikasi, hasil pemeriksaan dan lembar konsultasi.

Saat melakukan pengkodingan, beban kerja para petugas coder dapat mempengaruhi keakuratan kode. Penerapan kebijakan setiap bangsal memiliki coder menyebabkan beban kerja yang ditanggung pun berbeda di setiap bangsalnya. Berdasarkan penelitian terdahulu yang dilakukan oleh Octaria (2017) menghasilkan informasi bahwa kode diagnosis yang akurat $73,4 \%$, tidak akurat $26,3 \%$, beban tinggi $22,8 \%$, beban kerja tidak tinggi $77,2 \%$ serta terdapat hubungan beban kerja dengan keakuratan kode $(\mathrm{p}<0,05)$.

Keakuratan kode diagnosis di rumah sakit umum lebih baik dibandingkan dengan rumah sakit khusus, akan tetapi jumlah kode diagnosis dengan tipe kesalahan besar di rumah sakit umum lebih banyak (Farzandipour et al., 2010). Rumah Sakit Umum Daerah (RSUD) Dr. Moewardi merupakan rumah sakit umum negeri bertipe A dan telah terakreditasi paripurna. Persentase ketidaktepatan kode diagnosis tersebut lebih tinggi dibandingkan rata-rata rumah sakit dalam negeri lainnya yaitu 31,5\% (Arifianto et al., 2011; Rahayu et al., 2011; Rohman et al., 2011; Abiyasa et al., 2012; Ifalahma, 2013; Sarwastutik, 2013; Pujihastuti dan Sudra, 2014; Seruni dan Sugiarsi, 2015; Karimah et al., 2016) dan masih sangat jauh lebih tinggi dibandingkan dengan rumah sakit di luar negeri yaitu 12,71\% (Farzandipour et al., 2010; Cheng et al., 2009; Dalal dan Roy, 2009; Thigpen et al., 2015; Cummings et al., 2011).

Rumah Sakit Umum Daerah Dr. Moewardi terdapat beberapa bangsal salah satunya adalah bangsal melati yang dibagi menjadi tiga bangsal yaitu bangsal melati I, bangsal melati II, bangsal melati III yang masingmasing bangsal terdapat 1 coder. Setelah melakukan survei pendahuluan, peneliti mendapatkan hasil bahwa beban kerja coder dari masing-masing bangsal sangat beragam dan dari 10 dokumen terdapat $40 \%$ dokumen rekam medis tidak akurat.

Berdasarkan permasalahan tersebut maka peneliti tertarik untuk melakukan penelitian tentang "Hubungan Beban Kerja Coder dengan Keakuratan Kode Diagnosis Pada Pasien Rawat Inap Bangsal Melati di Rumah Sakit Umum Daerah Dr. Moewardi Surakarta Tahun 2018".

\section{METODE}

Jenis penelitian ini adalah penelitian analitik observasional dengan desain cross sectional. Populasi penelitian adalah seluruh dokumen rekam medis pasien rawat inap di Rsud Dr. Moewardi Surakarta tahun 2018 sejumlah 7.835 dokumen. Jumlah sampel dalam penelitian ditentukan dengan rumus Slovin dan didapatkan sampel sejumlah 99 dokumen rekam medis yang dipilih secara proportionate stratified random sampling. Data dikumpulkan menggunakan tabel observasi, lembar analisis beban kerja coder, lembar analisis keakuratan kode diagnosis dan ICD10. Data di analisis dengan univariat dan bivariat dengan chi-square.

\section{HASIL}

\section{Jumlah dan Persentase Beban Kerja}

\section{a. Menetapkan Waktu Kerja Tersedia}

Waktu kerja tersedia adalah waktu yang dipergunakan untuk melaksanakan tugas dan kegiatan dalam kurun waktu 1 tahun. Berikut merupakan waktu kerja tersedia yang telah dihitung :

\section{Tabel 1. Waktu Kerja Tersedia}

\begin{tabular}{|c|c|c|c|c|}
\hline No. & Komponen & Keterangan & Jumlah & Satuan \\
\hline 1. & Hari Kerja & 5 hari & 260 & Hari/tahun \\
\hline 2. & & 6 hari & 312 & Hari/tahun \\
\hline 3. & Cuti Pegawai & $\begin{array}{c}\text { Peraturan } \\
\text { kepegawaian }\end{array}$ & 12 & Hari/tahun \\
\hline 4. & Libur Nasional & $\begin{array}{l}\text { Dalam } 1 \text { tahun } \\
\text { (Kalender) }\end{array}$ & 19 & Hari/tahun \\
\hline 5. & $\begin{array}{l}\text { Mengikuti } \\
\text { Pelatihan }\end{array}$ & $\begin{array}{c}\text { Rata-rata dalam } \\
1 \text { tahun }\end{array}$ & 5 & Hari/tahun \\
\hline 6. & $\begin{array}{l}\text { Absen (Sakit, } \\
\text { dll) }\end{array}$ & & 12 & Hari/tahun \\
\hline 7. & $\begin{array}{l}\text { Waktu Kerja } \\
\text { (dalam } 1 \\
\text { minggu) }\end{array}$ & $\begin{array}{c}\text { Kepres No. } \\
68 / 1995\end{array}$ & 37.5 & Jam/minggu \\
\hline 8. & $\begin{array}{l}\text { Jam Kerja } \\
\text { Efektif }\end{array}$ & $\begin{array}{c}\text { Permen PAN- } \\
\text { RB 26/2011 }\end{array}$ & 26.25 & Jam/minggu \\
\hline 9. & Waktu Kerja & 5 hari/kerja & 5.25 & Jam/hari \\
\hline 10. & (dalam 1 hari) & 6 hari/kerja & 4.375 & Jam/hari \\
\hline
\end{tabular}




\begin{tabular}{|c|c|c|c|}
\hline 11. Waktu Kerja & 5 hari/kerja & 212 & Hari/tahun \\
\hline 12. Tersedia (hari) & 6 hari/kerja & 264 & Hari/tahun \\
\hline 13. Waktu Kerja & 5 hari/kerja & 1.113 & $\mathrm{Jam} /$ tahun \\
\hline 14. Tersedia (hari) & 6 hari/kerja & 1.155 & $\mathrm{Jam} /$ tahun \\
\hline \multicolumn{2}{|c|}{$\begin{array}{c}\text { Waktu kerja tersedia dibulatkan } \\
\text { (dalam jam) }\end{array}$} & 1.200 & Jam/tahun \\
\hline \multicolumn{2}{|c|}{$\begin{array}{l}\text { Waktu kerja tersedia dibulatkan } \\
\text { (dalam menit) }\end{array}$} & 72.000 & Menit/tahun \\
\hline
\end{tabular}

b. Menetapkan Komponen Beban Kerja dan Norma Waktu

Komponen beban kerja adalah jenis tugas dan uraian tugas yang secara nyata dilaksanakan oleh jenis petugas tertentu sesuai dengan tuas pokok dan fungsi yang telah ditetapkan. Berikut hasil meneliti komponen beban kerja dan norma waktu di bangsal Melati :

Tabel 2. Komponen Beban Kerja dan Norma Waktu

\begin{tabular}{|c|c|c|c|c|}
\hline No & Bangsal & Kegiatan & $\begin{array}{c}\text { Norma Waktu } \\
\text { (menit/dok) }\end{array}$ & Jumlah \\
\hline \multirow{4}{*}{1.} & \multirow{4}{*}{ Melati I } & $\begin{array}{l}\text { Assesment } \\
1 \times 24 \text { jam }\end{array}$ & 2 & \multirow{4}{*}{31} \\
\hline & & Koding & 21 & \\
\hline & & $\begin{array}{l}\text { Melengkapi } \\
\text { berkas klaim }\end{array}$ & 5 & \\
\hline & & Pra-grouping & 3 & \\
\hline \multirow{4}{*}{2.} & \multirow{4}{*}{ Melati II } & $\begin{array}{l}\text { Assesment } \\
1 \times 24 \text { jam }\end{array}$ & 1 & \multirow{4}{*}{20} \\
\hline & & Koding & 6 & \\
\hline & & $\begin{array}{l}\text { Melengkapi } \\
\text { berkas klaim }\end{array}$ & 10 & \\
\hline & & Pra-grouping & 3 & \\
\hline \multirow{4}{*}{3.} & \multirow{4}{*}{ Melati III } & $\begin{array}{l}\text { Assesment } \\
1 \times 24 \text { jam }\end{array}$ & 2 & \multirow{4}{*}{30} \\
\hline & & Koding & 11 & \\
\hline & & $\begin{array}{l}\text { Melengkapi } \\
\text { berkas klaim }\end{array}$ & 14 & \\
\hline & & Pra-grouping & 3 & \\
\hline
\end{tabular}

Berdasarkan penelitian di atas didapatkan hasil norma waktu bangsal Melati I yaitu 31 menit/ dokumen, bangsal Melati II yaitu 20 menit/ dokumen dan bansal Melati III yaitu 30 menit/ dokumen.

\section{c. Menetapkan Standar Beban Kerja}

Standar beban kerja coder merupakan data yang diperoleh dengan meneliti 9 dokumen rekam medis dari hasil pengamatan data primer bangsal Melati di Rumah Sakit Umum Daerah Dr. Moewardi. Berdasarkan penelitian tersebut dihasilkan standar beban kerja seperti pada tabel berikut :
Tabel 3. Standar Beban Kerja

\begin{tabular}{lccccc}
\hline No. & Bangsal & $\begin{array}{c}\text { Norma } \\
\text { Waktu }\end{array}$ & $\begin{array}{c}\text { Satuan } \\
\text { (menit/dok) }\end{array}$ & $\begin{array}{c}\text { WKT } \\
\text { (menit) }\end{array}$ & SBK \\
\hline 1. & Melati I & 31 & (menit/dok) & 72.000 & 2.322 \\
2. & Melati II & 20 & (menit/dok) & 72.000 & 3.600 \\
3. & Melati III & 30 & (menit/dok) & 72.000 & 2.400 \\
\hline
\end{tabular}

Berdasarkan penelitian terhadap 9 dokumen rekam medis pasien rawat inap bangsal Melati didapatkan hasil Standar Beban Kerja untuk bangsal Melati I yaitu 2322 dokumen, bangsal Melati II yaitu 3600 dokumen dan bangsal Melati III yaitu 2400 dokumen. Selanjutnya hasil Standar Beban Kerja perbangsal dibandingkan dengan jumlah kunjungan pada bangsal Melati selama 1 tahun.

c. Menetapkan Kategori Beban Kerja di Bangsal Melati

Beban Kerja bangsal Melati merupakan data yang diperoleh dari hasil Standar Beban Kerja yang dibandingkan dengan jumlah kunjungan pada tahun 2018. Berdasarkan penelitian tesebut dihasilkan kategori beban kerja di setiap bangsal Melati sebagai berikut :

Tabel 4. Kategori Beban Kerja

\begin{tabular}{ccccc}
\hline No. & Bangsal & $\begin{array}{c}\text { Standar } \\
\text { Beban Kerja }\end{array}$ & $\begin{array}{c}\text { Jumlah } \\
\text { Kunjungan }\end{array}$ & Kesimpulan \\
\hline 1. & Melati I & 2.322 & 901 & Rendah \\
2. & Melati II & 3.600 & 3.817 & Rendah \\
3. & Melati III & 2.400 & 3.117 & Tinggi \\
\hline
\end{tabular}

Berdasarkan tabel di atas, dapat diketahui Beban Kerja pada Bangsal Melati di Rumah Sakit Umum Daerah Dr. Moewardi Tahun 2018 terdapat bahwa beban kerja di bangsal Melati I dan bangsal Melati II yaitu rendah serta Melati III beban kerjanya tinggi.

\section{Jumlah dan Persentase Keakuratan dan Ketida- kakuratan Kode Diagnosis}

Keakuratan dan Ketidakakuratan kode merupakan data yang diperoleh dengan meneliti 99 dokumen rekam medis dari hasil pengamatan data primer bangsal Melati di Rumah Sakit Umum Daerah Dr. Moewardi. Berdasarkan penelitian ini dihasilkan kode yang akurat dan tidak akurat dengan presentase sebagai berikut : 


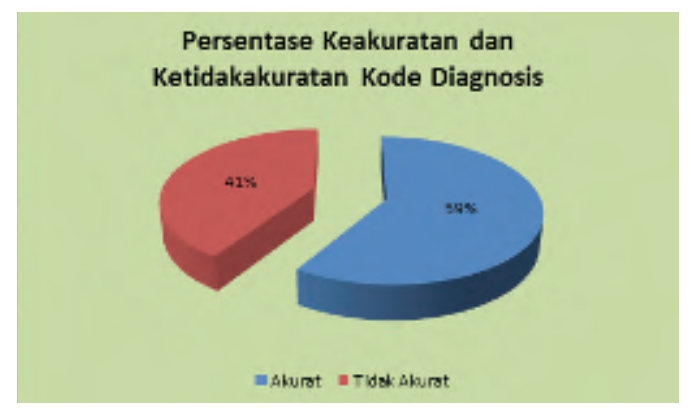

Gambar 1. Grafik Persentase Keakuratan dan Ketidakakuratan Kode Diagnosis

Berdasarkan Gb 1 dapat dilihat bahwa persentase keakuratan dan ketidakakuratan kode diagnosis pada bangsal Melati ada 59\% (58) dokumen akurat dan $41 \%$ (41) dokumen tidak akurat.

Klasifikasi ketidakakuratan kode diagnosis yang diambil dari 99 sampel dikelompokkan menjadi dua klasifikasi kode yang tidak akurat yaitu ketidakakuratan karena tidak dikode dan ketidakakuratan karena salah kode. Persentase ketidakakuratan dapat diklasifikasikan sebagai berikut:

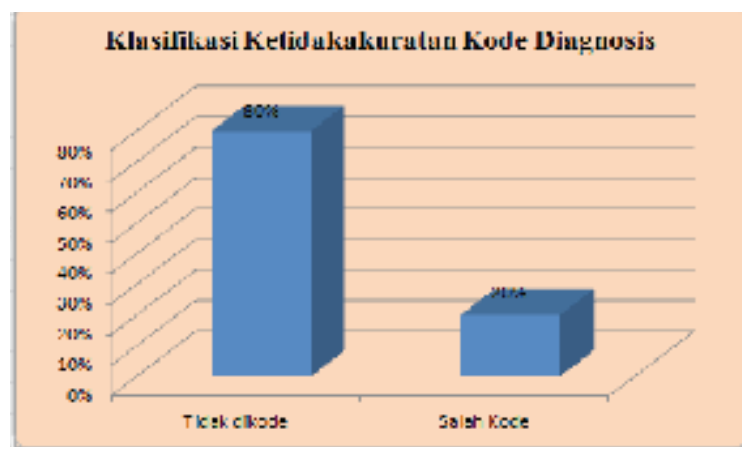

Gambar 2. Grafik Klasifikasi Ketidakakuratan Kode Diagnosis

\section{Hubungan Beban Kerja dengan Keakuratan Kode Diagnosis}

Berdasarkan observasi yang dilakukan terhadap Beban Kerja dengan keakuratan kode diagnosis pada dokumen rekam medis pasien rawat inap Bangsal Melati di Rumah Sakit Umum Daerah Dr. Moewardi Tahun 2018 didapatkan hasil sebagai berikut :

Tabel 5. Tabulasi Silang Beban Kerja Dengan Keakuratan Kode Diagnosis

\begin{tabular}{|c|c|c|c|c|c|c|c|c|}
\hline 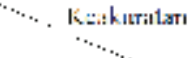 & \multicolumn{2}{|c|}{ Alkuzal } & \multicolumn{2}{|c|}{$\begin{array}{l}\text { Tidaj: } \\
\text { Akuta1 }\end{array}$} & \multicolumn{2}{|c|}{ Totul } & & \multirow{2}{*}{$\begin{array}{l}\text { Odidis } \\
\text { Ri:liis }\end{array}$} \\
\hline cban Ketji & $\mathrm{N}$ & $\%$ & $\mathrm{~N}$ & $\%$ & $N$ & $\%$ & & \\
\hline Rendah & 16 & $78 \%$ & 13 & $23 \%$ & 59 & $100 \%$ & Difirt & 1) $5 \pi$ \\
\hline Tักนม। & 12 & $30{ }^{3}$ & IX & $70 \%$ & $4 !)$ & {$[101)^{6 / 4}$} & & \\
\hline
\end{tabular}

Berdasarkan hasil perhitungan menggunakan uji statistik Chi Square dapat diketahui nilai $\rho<0,01$ sehingga dapat ditarik kesimpulan yaitu Ho ditolak, maka dapat dikatakan bahwa terdapat hubungan beban kerja dengan keakuratan kode diagnosis pada Bangsal Melati di Rumah Sakit Umum Daerah Dr. Moewardi Tahun 2018.

\section{PEMBAHASAN}

Tinggi atau rendahnya beban kerja dapat diukur berdasarkan perbandingan antara beban kerja yang ada terhadap standar beban kerja yang dihitung menggunakan rumus yang sudah ditetapkan. Beban kerja dapat dikatakan rendah jika tidak melebihi dari standar beban kerja dan beban kerja yang tinggi jika melebihi standar beban kerjanya. Berdasarkan hasil observasi yang telah dilakukan dapat diketahui bahwa beban kerja pada bangsal Melati I dan bangsal Melati II dikategorikan rendah, sedangkan beban kerja pada bangsal Melati III dikategorikan tinggi.

Pekerjaan yang dirangkap oleh coder berupa assesment awal 1×24 jam, coding, pra-coding/ pra-grouper dan melengkapi berkas rekam medis. Assessment 1×24 jam merupakan audit berkas rekam medis pasien rawat inap yang akan keluar dari rumah sakit. Pra-coding / pra-grouper merupakan kegiatan memasukkan kode penyakit dan tindakan saat pasien masih rawat inap, sedangkan melengkapi berkas rekam medis yaitu kegiatan melengkapi dokumen rekam medis seperti tanda tangan dokter penanggung jawab dan hasil pemeriksaan penunjang.

Alasan bangsal Melati II jumlah dokumennya banyak namun beban kerjanya rendah karena bangsal Melati II merupakan bangsal khusus anak yang tingkat kesulitan dalam mengkode lebih mudah sehingga dikejakan lebih cepat sedangkan alasan bangsal Melati III jumlah dokumennya sedikit namun beban kerjanya tinggi karena bangsal Melati III merupakan bangsal yang menangani kasus Interna khususnya Neoplasma dengan komplikasi berat sehingga tingkat kesulitan dalam mengkode lebih sulit.

Menurut Moekijat (2011) yang menyebutkan bahwa Beban kerja yang didistribusikan secara tidak merata dapat mengakibatkan ketidaknyamanan suasana kerja karena karyawan merasa beban kerja yang dilakukannya terlalu berlebihan atau bahkan kekurangan. Standar beban kerja menunjukkan betapa banyak pekerjaan yang diharapkan dari tiap pegawai.

Ketidaktepatan kode diagnosis di bangsal Melati 
mencapai 41\%. Faktor yang dapat mempengaruhi salah penetapan kode diagnosis tersebut adalah kelengkapan dokumen rekam medis termasuk hasil pemeriksaan penunjangnya. Kelengkapan informasi medis dan keakuratan dokumen rekam medis sangatlah penting, jika informasi medis dalam suatu dokumen rekam medis tidak lengkap, maka kode diagnosis yang dihasilkan menjadi tidak akurat (Maryati et al, 2019).

Pengkode harus mampu menetapkan kode diagnosis dengan baik sesuai klasifikasi penyakit yang berlaku di Indonesia yaitu International Statistical Classification of Diseases and Related Health Problems 10 ${ }^{\text {th }}$ Revision (ICD-10) (Hatta, 2014). Apabila terdapat diagnosis yang tidak dikode menunjukkan bahwa Rumah Sakit perlu menetapkan kebijakan bahwa kodefikasi diagnosis merupakan kewajiban dari pengkode (Maryati et al, 2016).

Hasil analisis Chi-square menunjukkan bahwa terdapat hubungan yang signifikan antara beban kerja coder dengan keakuratan kode diganosis. Tabulasi silang juga telah menunjukkan bahwa semakin tinggi beban kerja coder akan meningkatkan ketidakakuratan kode diagnosis. Seperti pada Tabel 3.5 di atas, beban kerja coder yang tinggi menghasilkan ketidakakuratan kode diagnosis lebih besar yaitu 70\%, dibandingkan dengan beban kerja coder rendah yang hanya menghasilkan ketidakakuratan kode diagnosis 22\%. Pernyataan di atas sama seperti penelitian yang telah dilakukan oleh Oktaria (2017) yang menyebutkan beban kerja coder mempengaruhi keakuratan kode diagnosis pasien rawat inap.

\section{SIMPULAN}

Ada hubungan beban kerja dengan keakuratan kode diagnosis pada bangsal Melati di Rumah Sakit Umum Daerah Dr. Moewardi tahun 2018. Sebaiknya rumah sakit merencanakan kebutuhan coder dan menganalisis beban kerja coder di masing-masing bangsal karena beban kerja pebangsal berbeda-beda agar keakuratan kode diagnosis semakin optimal.

\section{UCAPAN TERIMA KASIH}

Pada kesempatan ini, penulis mengucapkan terimakasih kepada Rektor Universitas Duta Bangsa Surakarta yang telah memberikan dukungan untuk publikasi artikel ini.

\section{DAFTAR PUSTAKA}

Abiyasa MT, Ernawati D, Kresnowati L. (2012). Hubungan antara Spesifitas Penulisan Diagnosis terhadap Akurasi Kode pada RM 1 Dokumen Rawat Inap Rumah Sakit Bhayangkara Semarang. Jurnal Visikes. 11(2): 99-104.

Arifianto E, Kresnowati L, Ernawati D. (2011). Keakuratan Kode Diagnosa Utama Dokumen Rekam Medis pada Kasus Partus dengan Sectio Cesarean di Rumah Sakit Panti Wilasa Citarum. Jurnal Visikes. 10(2): 84-88.

Cheng P, Gilchrist A, Robinson KM, Paul L. (2009). The Risk and Consequences of Clinical Miscoding Due to Inadequate Medical Documentation: A Case Study of The Impact on Health Services Funding. HIMJ. 38(1): 35-46.

Cummings E, Maher R, Showell CM, Croft T, Tolman J, Vickers J, Stirling C, Robinson A, Turner P. (2011). Hospital Coding of Dementia: Is It Accurate. Health Information Management Journal. 40(3): 5-11.

Dalal S, Roy B. (2009). Reliability of Clinical Coding of Hip Fracture Surgery: Implications for Payment by Results. International Journal Care Injured. 40 (1): 738-741.

Farzandipour M, Sheikhtaheri A, Sadoughi F. (2010). Effective Factors on Accuracy of Principal Diagnosis Coding Based on International Classification of Diseases, The 10th Revision (ICD-10). International Journal of Information Management. 30: 78-84.

Hatta, G.R. (2014). Pedoman Manajemen Informasi Kesehatan di Sarana Pelayanan Kesehatan. Jakarta : Universitas Indonesia.

Ifalahma D. (2013). Hubungan Pengetahuan Coder dengan Keakuratan Kode Diagnosis Pasien Rawat Inap Jaminan Kesehatan Masyarakat Berdasarkan ICD-10 Di RSUD Simo, Boyolali. Jurnal INFOKES. 3(2): 14-26.

Karimah RN, Setiawan D, Nurmalia PS. (2016). Analisis Ketepatan Kode Diagnosis Penyakit Gastroenteritis Acute Berdasarkan Dokumen Rekam Medis di Rumah Sakit Balung, Jember. Journal of Agromedicine and Medical Sciences. 2(2): 12-17. 
Kasim, F. (2011). Sistem Klasifikasi Utama Morbiditas dan Mortalitas. Jakarta: UI Press

Maryati, W., Murti, B., Indarto, D. (2016). Factors Affecting the Quality of Diagnosis Coding and Medical Record at Dr. Moewardi Hospital, Surakarta. Journal of Health Policy and Management, 1(2): 61-70.

Maryati, W., Rahayuningrum, I.O., Justika, A.I. (2019). Quality of medical information determine the quality of diagnosis code. International Journal of Public Health Science, 8 (3) : 326-331.

Menteri Kesehatan RI. (2007). Keputusan Menteri Kesehatan Republik Indonesia Nomor 377/Menkes/SK/III/2007 Tentang Standar Kompetensi Perekam Medis dan Informasi Kesehatan. Jakarta : Menkes RI.

Moekijat. (2010). Manajemen Sumber Daya Manusia. Bandung : Mandar Maju.

Octaria, H. (2017). Hubungan Beban Kerja Coder dengan Keakuratan Kode Diagnosa Pasien Rawat Inap di Rumah Sakit Syarifa Pekanbaru. Jurnal Manajemen Informasi Kesehatan Indonesia, 5 (1) : 92-95.

Pujihastuti A, Sudra RI. (2014). Hubungan Kelengkapan Informasi dengan Keakuratan Kode Diagnosis dan Tindakan pada Dokumen Rekam Medis Rawat Inap. Jurnal Manajemen Informasi Kesehatan Indonesia. 3(1): 60-64.

Rahayu H, Ernawati D, Kresnowati L. (2011). Akurasi Kode Diagnosis Utama pada RM 1 Dokumen Rekam Medis Ruang Karmel dan
Karakteristik Petugas Koding Rawat Inap Rumah Sakit Mardi Rahayu Kudus Periode Desember 2009. Jurnal Visikes. 10(1): 1-5.

Republik Indonesia. (2009). Undang-undang No.44 Tahun 2009 tentang Rumah Sakit. Jakarta: Republik Indonesia.

Rohman H, Hariyono W, Rosyidah. (2011). Kebijakan Pengisian Diagnosis Utama dan Keakuratan Kode Diagnosis pada Rekam Medis di Rumah Sakit PKU Muhammadiyah Yogyakarta. Jurnal KESMAS. 5(2): 162-232.

Sarwastutik. (2013). Tinjauan Keakuratan Kode Diagnosis pada Dokumen Rekam Medis Pasien Rawat Inap dengan Kondisi Utama Typhoid Fever Berdasarkan ICD-X di RSU PKU Muhammadiyah Delanggu. Jurnal INFOKES. 3(2): 8-13.

Seruni FDA, Sugiarsi S. (2015). Problem Solving Cycle Swot Keakuratan Kode Diagnosis Kasus Obstetri pada Lembar Masuk dan Keluar (RM 1a) Pasien Rawat Inap di RSUD Dr. Sayidiman Magetan. Jurnal Manajemen Informasi Kesehatan Indonesia. 3(2): 5-13.

Sudra, R.I. (2014). Rekam Medis. Tangerang Selatan: Universitas Terbuka.

Thigpen JL, Pharm, Dillon C, Forster KB, Henault L, Quinn EK, Tripodis Y, Berger PB, Hylek EM, Limdi NA. (2015). Validity of International Classification of Disease Codes to Identify Ischemic Stroke and Intracranial Hemorrhage Among Individuals with Associated Diagnosis of Atrial Fibrillation. Circ Cardiovasc Qual Outcomes. 8(1): 8-14. 